Abeysinghe, N.S.D., Senaratne, S. and Andaraweera, A.K., 2019. Managing knowledge through social networks within multi-national real estate consultancy firms: A literature review. In: Sandanayake, Y.G., Gunatilake, S. and Waidyasekara, A. (eds). Proceedings of the $8^{\text {th }}$ World Construction Symposium, Colombo, Sri Lanka, 8-10 November 2019, pp. 422-430. DOI: doi.org/10.31705/WCS.2019.42. Available at: https://2019.ciobwcs.com/papers

\title{
MANAGING KNOWLEDGE THROUGH SOCIAL NETWORKS WITHIN MULTI- NATIONAL REAL ESTATE CONSULTANCY FIRMS: A LITERATURE REVIEW
}

\author{
N.S.D. Abeysinghe ${ }^{1}$, S. Senaratne ${ }^{2}$ and A.K. Andaraweera ${ }^{3}$
}

\begin{abstract}
Multinational Real Estate Consultancy Firms (MNRECF), as "knowledge-based entities", has progressively distributed their operations to their branches all around the world. Disseminated knowledge expertise across borders may, on the one h, benefit MNRECFs due to its' multiplicity, but, on the other h, may be difficult to orchestrate. Thus, orchestration of the knowledge across dispersed unit's conversion of those into innovation competences has become a crucial capability for MNRECFs. Transferring knowledge through one-to-one conversations has been threatened by the increasing movement of the consultants of MNRECFs across different countries. Since the evolution of network relationships has impacted most companies in the modern economy setting, Social Network concept has become the focus of many companies. Organizations' tacit knowledge sharing is mainly structurally supported by the social networking. In MNRECFs, members belong to one category or department dispersed in widespread locations. Therefore, there is a wide adoption of Enterprise Social Networking (ESN) as a collaborative Knowledge Management (KM) tool. The paper suggests the KM efforts within MNRECFs should identify the 'Influencers' in the social network in order to introduce encourage the participation of more actors to the ESN. Therefore, the paper details social networks' features provide an account of relevant combination of ESN SNA facilitated KM initiatives within MNRECFs.
\end{abstract}

Keywords: Enterprise Social Networks; Influencers; Knowledge Management; Multinational Real Estate Consultancy Firms; Social Networks; Social Network Analysis.

\section{INTRODUCTION}

Multi-National Real Estate Consultancy Firms (MNRECF) largely depends on the specialised knowledge of their expert professionals, nature of the business requires them to move across different locations, countries, knowledge transferring using one-oneconversation has become challenging as a result (Senaratne et al., 2018). Therefore, a need has arisen in these organizations for the knowledge to be systematically managed in order to overcome the limitations arising from the common uneven distribution of knowledge (Senaratne et al., 2018).

\footnotetext{
${ }^{1}$ Silk Road Partners (Pvt) Ltd, Sri Lanka, nelushi@silkroadpartners.lk

${ }^{2}$ University of Western Sydney, Australia, S.Senaratne@westernsydney.edu.au

${ }^{3}$ Orion Development (Pvt) Ltd, Sri Lanka, amiyuk2000@yahoo.com
} 
Tacit knowledge sharing in Companies are mainly supported by the social networking (Churchill and Halverson, 2005). As stated MNRECFs' consultants are spread across several countries, therefore there is a strong requirement for flexible easy to deploy collaborative KM tools (Senaratne et al., 2018).

The aim of this research is to review the role of social networks in knowledge management in the business context of multi-national real estate consultancy firms. The aim is accomplished by following the subsequent steps: reviewing the concept of Knowledge Management in Multinational Companies and Multinational Real Estate Consultancy Firms, identifying Enterprise Social Networks as a key ingredient of knowledge management in multi-national real estate consultancy firms, identifying discussing benefits of adopting Enterprise Social Networks as a Knowledge Management Tool in MNRECFs providing a set of relevant collaborative knowledge management tools for Influencer identification in ESN of the MNRECFs using SNA in the context of multi-national real estate consultancy firms. Since nature of knowledge is not well defined in MNRECFs context, the role of social networks in knowledge management in the business context of MNRECFs is not well understood. This created the knowledge gap for this research emerged the research question for the study. Accordingly, the research question for the study is, "What is the role of social networks in knowledge management in the business context of multi-national real estate consultancy firms?'.

\section{RESEARCH METHODOLOGY}

Among the several Literature review methods available 'integrative review' is selected for this research. Integrative review, reviews, analyses, critiques synthesizes data about a research topic in an integrated way such that new frameworks viewpoints on the topic are produced (Russell, 2005). The 5 Stage integrative review process includes 1) problem formulation, (2) data collection or literature search, (3) evaluation of data, (4) data analysis, (5) interpretation presentation of results (Russell, 2005). The nature of the research requires a comprehensive methodological approach of reviews in order to analysis the problem to create a consistent comprehensive view of the concepts, problems most importantly to fully underset the research areas addressed. Integrative review method clearly facilitates the aforesaid requirement as it is the most comprehensive procedural approach of reviews, it allows including experimental non-experimental studies to fully understand the phenomenon analysed. It also combines data from theoretical empirical literature, has a wide range of purposes, such as definition of concepts, review of theories evidence, analysis of methodological problems of a particular topic (Russell, 2005).

\section{KNOWLEDGE MANAGEMENT IN MULTINATIONAL COMPANIES}

Within the past few years, Multi-National Companies (MNC) have identified KM as one of the main sources of competitive advantage (Scott, 1991). MNC provide the ideal platform which is required for the implantation of KM process (as depict in Figure 1) as its' resources are spanned across several courtiers (Alavi and Leidner, 2001). KM processes enable MNC's knowledge to be used in an optimum way while creating value (Ferraris et al., 2017). 
Crespo, Griffith and Lages (2014), describes MNC as a corporation "formed by multiple knowledge units, where each subsidiary serves as a key knowledge node (refer Figure 1) capable of acquiring, converting, transferring knowledge throughout the firm". Globalisation is the main driver for resource distribution in MNCs which can be used to obtain competitive advantage (Scott, 1991). Knowledge internal capabilities of subsidiaries of MNCs' most often poses competitive advantage not only for the subsidiary itself but throughout the whole MNC, shown in Figure 1 (Inpken et al., 2018).

\section{KNOWLEDGE MANAGEMENT IN MULTINATIONAL REAL ESTATE CONSULTANCY FIRMS}

Corporate Real Estate (CRE), as a discipline is continuously evolving in order to cater the deems of emerging markets of developing countries which have experienced a fasteconomic growth over the last two decades (Mutreja et al., 2015). As a result, MNRECFs in the emerging markets has continued to flourish, which has resulted in rapid increase of number of CRE professional who are deployed in all aspects of real estate consultancy; transactions, facilities management, project management portfolio planning management (Piscitello and Rabbiosi, 2004).

For MNRECFs availability of updated reliable data obtained from wide variety of sources are crucial in providing real estate solutions to their Clients as Client services related decision making requires incisive analysis of market trends, key market practices, risks opportunities (Gupta and Govindarajan, 1991). Suitable research is required for Scenario building good forecasting as well (Gupta and Govindarajan, 1991). In order to address the above needs MNRECFs have established dedicated market research teams in central dispersed locations, with the main duty of issuing regular reports to all other entities in different geographies (Meyer et al., 2011).

Main source of receipt of knowledge for CRE professional in MNRECFs is through the internal networks mainly through parent firm subsidiaries (Ferraris, Santoro and Dezi, 2017). Hence, value-creation opportunities throughout the firm are generated mainly through knowledge creation in subsidiaries knowledge transfer which occurs within between subsidiaries (Asakawa and Lehrer, 2003). Importance of knowledge flow in MNRECFs has been highlighted in many recent studies (Nielsen and Michailova, 2007). The studies have also demonstrated how the roles of subsidiaries have changed from being merely the receivers of knowledge to becoming knowledge creators for the rest of the MNRECF's network (Bartlett and Goshal, 1989).

According to Seufert et al. (1999), "the key to obtaining long-term competitive advantage is not to be found in the administration of existing knowledge, but in the ability to constantly generate new knowledge." Therefore, it is crucial that branches of MNRECF acts as knowledge creators which enable them to introduce the new, exclusive, valuable knowledge, which can then be used by the rest of the MNRECF's network (Cantwell and Mudambi, 2004).

\section{SOCIAL NETWORK AND SOCIAL NETWORK ANALYSIS (SNA)}

A "Social Network" can be seen as: "a specific set of linkages among a defined set of actors, with the additional property that the characteristics of these linkages as a whole may be used to interpret the social behaviour of the actors involved" (Seufert et al., 1999). 
Social Network Analysis (SNA), in a many modern research fields it is considered as a key technique (Churchill and Halverson, 2005). It analyses social networks through network theory, which views social relationships in terms of nodes ties (Senaratne et al., 2018). Organizations are starting to include social networking features in their knowledge management structure in order to capture tacit, social, individual knowledge (Senaratne et al., 2018).

\section{ENTERPRISE SOCIAL NETWORKS AS A KNOWLEDGE MANAGEMENT TOOL}

Knowledge creation in organizations are largely depended on the interactions (Ellison, Gibbs and Weber, 2014). Enterprise Social Network (ESN) enable Organizations to involve users from all levels of the organization to interact share knowledge (shown in Figure 1), it comprises with an emerging set of software processes which provide a platform which is similar to social media (Bhatt, 2002). It has the capabilities designed to capture knowledge from social engagements within the platform (Nonaka et al., 2009). By offering a common platform for discussing novel concepts sharing experiences between individuals ESN facilitates continuous sharing of knowledge by linking facilitating actors in the network (Bhatt, 2002). ESN can contribute to the transferability of knowledge (Grant, 1996), which contributes to convert individual knowledge into organizational knowledge (Nonaka and Von Krogh, 2009).

ESN's functions includes broadcasting messages throughout the organization enable actors to communicate with particular co-workers easily securely; post, edit, sort text files linked to themselves or others; view the messages, connections, text, files communicated, posted, edited sorted by anyone else in their organization at any time of their choosing (Leonardi et al., 2013).

Many MNRECFs are starting to use ESNs applications such as Yammer, Ning, Jive, or Telligent; enterprise social media tools. Implementing ESN can benefit largely for Organizational process as it provides easy access to new expertise knowledge (DiMicco and Millen, 2007).

\section{ENTERPRISE SOCIAL NETWORKS AS A KNOWLEDGE MANAGEMENT TOOLS IN MNRECFS}

ESN provides diverse benefits to Organizations; provides different levels of controls (individualistic/collectivistic) level of interaction with respect to the creation of content (Razmerita et al., 2014). Individuals in control of content creation tools such as microblogs social network sites, allow people to efficiently accomplish tasks interactions (Razmerita et al., 2014). Tools with a collective focus, such as content community's wikis, offer a higher level of interaction in content creation (Steinfield et al., 2008).

Diversity of knowledge can be increased by creation of interactive content which in turn contribute to the externalization of knowledge (Ellison, Gibbs and Weber, 2014). As an outcome, knowledge sharing in an organization is generally followes an centralized intermittent knowledge management process, when using ESN it generates opportunities to covert the process it to an continuous knowledge conversation sharing that results in unexpected rousers, interpretation, dynamic emergence (Majchrzak et al., 2013). 
CRE professionals have a limited free time under an immense pressure to deliver services on time (O'Leary, 2015). Hence, in case if an information or a knowledge gap they prefer the least time-consuming route in order to fill the gap to get the job done (Steinfield et al., 2008). Therefore, unsurprisingly, practitioners will reject cumbersome or timeconsuming knowledge sources use relevant, useful, and easy to access content (O'Leary, 2015). In an ESN which is based on information technological platform user-generated content are disseminated real-time using short-texts (O'Leary, 2015). Due to that, time taken to share information across ESN is very limited (Majchrzak et al., 2013). Therefore, implementing information technology-based ESN platforms can add a lot of value to MNRCFs (O’Leary, 2015).

\section{CHALLENGES}

Although there has been a wide adoption of ESNs within MNCs, some potential concerns other issues are also been identified. One of the biggest challenges include the reluctance of some of the members to be active on the network (share information) presented in Figure 1, although they use the information which is available, the contribution to the knowledge from them is minimal (Aral et al., 2013). It restricts also the opportunity to learn new things for others (Aral et al., 2013). In addition to this, there is trend that members in the social network tend to follow members whom they already know (refer Figure 1), it creates a disadvantage that if those are been followed are not active members it prevents users from being open to new updated knowledge (Aral et al., 2013). This in turn may make the system appear "unengaging" and thereby discourage future active use limiting social capital benefits (Aral et al., 2013).

In order to enjoy the benefits of ESNs to its fullest, participation of large number of percentage of actors is required (Piscitello and Rabbiosi, 2004). However, as noted by Stewart (2012), "about 30 to 40 percent of employees where registration is required won't even register of the ones who do register another 40 to 50 percent will neither post very often or even read other people's comments when they are sent out" (refer Figure 1). The effectiveness of the KM process is been challenged if the density of the network is relatively less than the intended network density of the (Stewart, 2012). To overcome research studies in the area suggests to detect influencers in the ESN of the MNREF using Social Network Analysis (discussed below) encourage them to introduce more actors to the network to realize promised benefits of ESN (Stewart, 2012).

\section{INFLUENCER IDENTIFICATION IN ESN OF THE MNRECF USING SNA}

There are numerous descriptions of influencer, example: the most active participants, the participants who mostly answers other participants' questions, members who inspire others to participate in discussion topics projects (Fulk and Yuan, 2013). Influencer identification (refer Figure 1) is important to ensure full functionality of an ESN as those are the key players of a network who contribute largely in keeping ESN active alive (Ellison et al., 2014). Social networks impact is increased by the content created shared by the Influencers such as tutorials, subject related videos etc. hence, it is vital for Organizations to identify the Influencers encourage them to continue their tasks (Fulk and Yuan, 2013). Where there are only few members small ESNs are used, identification of influencers can be done easily by checking the members their posts manually (Ellison et al., 2014). In such a situation everyone know who-is-who in the network (Fulk and Yuan, 
2013). However, in a context which large number of members publish large number of posts daily computations tools becomes vital in identification of influencers (Ellison et al., 2014).

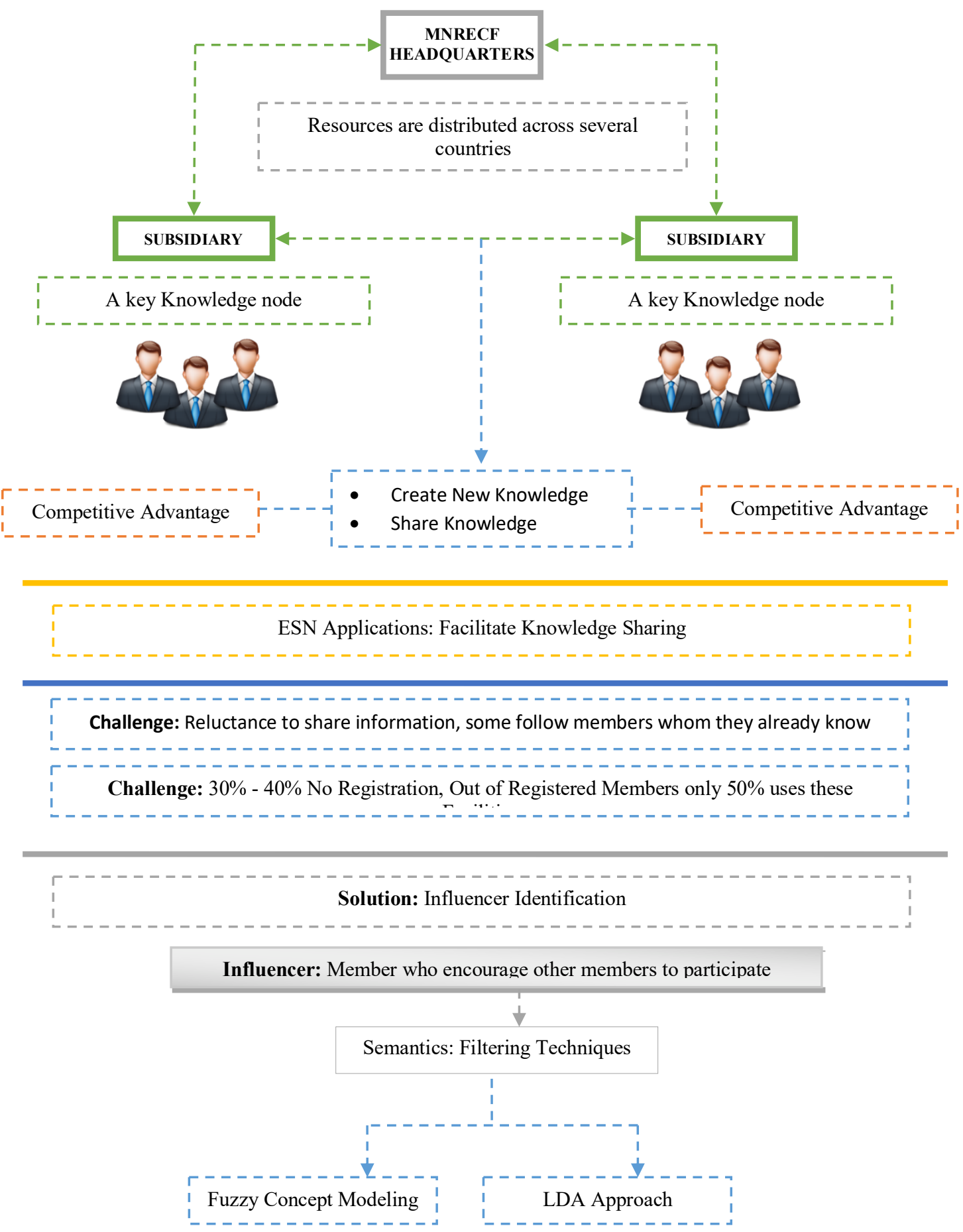

Figure 1: Social networking in MNRECFs

Common interest of a set of users can be understood by using information filtering systems which were developed by several researchers recently (Fang and Chiu, 2010). After the identification of common interest in a particular group those can be then be 
utilized to disseminate relevant content for those interest groups (Fang and Chiu, 2010). Same filtering techniques can be used to identify influencers in a network based on the semantics (Fang and Chiu, 2010). Semantics is the relevant information inferred from knowledge bases related to the content in short text, which can be used to facilitate better undersetting processing (Fang and Chiu, 2010). Rios et al. (2017), proposed two kinds of semantic filtering in order to spot the influencers in a social network, shown in Figure 1; one based on fuzzy concept modelling the other on topics discovered by LDA approach. When it comes to large networks the capability to scale up the detection method is important (Rios et al., 2017). Rios et al. (2017) is a research which proposed an approach which advances the scalability of the primary key-member recognition algorithm, in which the complexity is directly relational to the quantity of nodes actors, this could be explored in a further research. All findings are summarised in Figure 1.

\section{CONCLUSIONS}

Growth of Multi National Real Estate Consultancy Firms (MNRECF) in the emerging markets have resulted a phenomenal rise in the number Corporate Real Estate (CRE) professionals deployed in all aspects, increasing globalization has influenced an increasing number of MNRECFs to cross their local boundaries to establish branches in other countries. CRE professionals deem for relevant, useful, easy to access content, quickly and will reject sources that are cumbersome or time consuming. MNRECFs are starting to include social networking features in their knowledge management infrastructure to capture tacit, social, individual knowledge (O'Leary, 2015). In this context implementing ESN which is based on information technological platform is proposed as a solution for the consultants in MNRECFs.

Participation of a large number of members of the enterprise is requires to fully obtain the "network" benefits (Majchrzak et al., 2013). Effectiveness of the KM process is been challenged if the density of the network is comparatively less than the designed network density of the ESN which is made up of with the comparatively less set of social actors (Stewart, 2012). Influencer identification is crucial as those are the individuals who keep the ESN alive (Ellison, Gibbs and Weber, 2014). The research proposes two comprehensive ways to influence actors' behavior through overall operational features of social networks' (Fang and Chiu, 2010. Finding out the Influencer in a specific ESN requires application of influencer identification algorithms (Fang and Chiu, 2010).

\section{REFERENCES}

Alavi, M. and Leidner, D. E., 2001. Knowledge management knowledge management systems: Conceptual foundations research issues. MIS Quarterly, 25(1), pp.107-136.

Asakawa, K. and Lehrer, M., 2003. Managing local knowledge assets globally: The role of regional innovation relays. Journal of World Business, 38(1), pp.31-42.

Aral, S., Dellarocas, C. and Godes, D., (2013). Introduction to the Special Issue-Social Media Business Transformation: A Framework for Research. Information Systems Research, 24(1), pp.3-13.

Bartlett, C.A. and Ghoshal, S., 1989.Managing across Borders: The Transnational Solution. Boston: Harvard Business School Press.

Bhatt, G. D., 2002. Management strategies for individual knowledge organizational knowledge. Journal of Knowledge Management, 6(1), pp.31-39.

Cantwell J. A. and Mudambi R., 2004. Multinational enterprises competence-creating knowledge flows: a theoretical analysis. Knowledge Flows, Governance Multinational Enterprise. London: Palgrave Macmillan. 
Churchill, E. F. and Halverson, C. A., 2005. Social Networks Social Networking. IEEE Internet Computing, 9(5), pp.14-19.

Crespo, C.F., Griffith, D.A. and Lages, L.F., 2014. The performance effects of vertical horizontal subsidiary knowledge outflows in multinational corporations. International Business Review, 23(5), pp.993-1007.

DiMicco, J. M. and Millen, D. R., 2007. Identity management. Proceedings of the 2007 International ACM Conference on Conference on Supporting Group Work - GROUP '07, New York, pp.383-386.

Ellison, N. B., Gibbs, J. L. and Weber, M. S., 2014. The Use of Enterprise Social Network Sites for Knowledge Sharing in Distributed Organizations. American Behavioral Scientist, 59(1), pp.103-123.

Fang, Y. H. and Chiu, C. M., 2010. In justice we trust: Exploring knowledge-sharing continuance intentions in online communities of practice. Computers in Human Behavior, 26, pp.235-246.

Ferraris, A., Santoro, G. and Dezi, L., 2017. How MNC's subsidiaries may improve their innovative performance? The role of external sources knowledge management capabilities. Journal of Knowledge Management, 21(3), pp.540-552.

Fulk, J. and Yuan, Y.C., 2013. Location, motivation, social capitalization via enterprise social networking. Journal of Computer-Mediated Communication, 19(1), pp.20-37.

Grant R. M., 1996. Toward a Knowledge-based Theory of the Firm. Strategic Management Journal, 17, pp.109-22.

Gupta, A. K. and Govindarajan, V., 1991. Knowledge Flows the Structure of Control Within Multinational Corporations. Academy of Management Review, 16(4), pp.768-792.

Inkpen, A., Minbaeva, D. and Tsang, E. W. K., 2018. Unintentional, unavoidable, beneficial knowledge leakage from the multinational enterprise. Journal of International Business Studies, 50(2), pp.250260.

Leonardi, P. M. and Meyer, S. R., 2014. Social Media as Social Lubricant. American Behavioral Scientist, 59(1), pp.10-34.

Leonardi, P. M., Huysman, M., and Steinfield, C., 2013. Enterprise social media: Definition, history, prospects for the study of social technologies in organizations. Journal of Computer-Mediated Communication, 19, pp.1-19.

Majchrzak, A., Faraj, S., Kane, G.C. and Azad, B., 2013. The contradictory influence of social media affordances on online communal knowledge sharing. Journal of Computer-Mediated Communication, 19(1), pp.38-55.

Meyer, K.E., Mudambi, R. and Narula, R., 2011. Multinational enterprises local contexts: the opportunities and challenges of multiple embeddedness. Journal of Management Studies, 48(2), pp.235-252.

Mutreja, R., Chua, M.L., and Guha, A., 2015. The role of corporate real estate in developing countries of the Asia-Pacific region. Corporate Real Estate Journal, 4(4), pp.314-322.

Nielsen, B. B., and Michailova, S., 2007. Knowledge Management Systems in Multinational Corporations: Typology Transitional Dynamics. Long Range Planning, 40(3), pp.314-340.

Nonaka, I. and Von Krogh, G., 2009. Perspective-tacit knowledge conversion: Controversy advancement in organizational knowledge creation theory. Organization science, 20(3), pp.635-652.

O’Leary, D. E., 2015. Knowledge Management Enterprise Social Networking: Content versus Collaboration. Intelligent Systems Reference Library, 95, pp.45-74.

Piscitello, L. and Rabbiosi, L., 2004. The impact of MNCs; foreign activities on the innovative performance of the parent companies, DRUID Summer Conference, Elsinore 14-16 June 2004.

Razmerita, L., Kirchner, K. and Nabeth, T., 2014. Social Media in Organizations: Leveraging Personal Collective Knowledge Processes. Journal of Organizational Computing Electronic Commerce, 24(1), pp.74-93.

Ríos, S.A., Aguilera, F., Nuñez-Gonzalez, J.D. and Graña, M., 2019. Semantically enhanced network analysis for influencer identification in online social networks. Neurocomputing, 326, pp.71-81.

Russell, C. L., 2005. An overview of the integrative research review. Progress in transplantation, 15(1), pp.8-13.

Scott, J., 1991. Networks of Corporate Power: A Comparative Assessment. Annual Review of Sociology, 17(1), pp.181-203. 
Senaratne, S., Abeysinghe, N.S.D. and Andaraweera, A.K., 2018. Social Networks for Knowledge Management in Multinational Real Estate Consultancy Firms - A Literature Review. $11^{\text {th }}$ International Conference of Faculty of Architecture Research Unit, 08 December 2018, Galle: Faculty of Architecture Research Unit-University of Moratuwa, pp.9-16.

Seufert, A., von Grogh, G. and Bach, A., 1999. Towards knowledge Networking. Journal of Knowledge Management, 3(3), pp.180-190.

Steinfield, C., Ellison, N. B., and Lampe, C. 2008. Social capital, self-esteem, use of online social network sites: A longitudinal analysis. Journal of Applied Developmental Psychology, 29, pp.434-445.

Stewart, D., 2012. Enterprise social networks: useful tool, not a Panacea [Online]. Available from: https://deloitte.wsj.com/cio/2013/02/21/enterprise-social-networks-another-tool-not-a-panacea/ [Accessed 02 January 2019]. 